\title{
ANALISIS USAHA PERIKANAN PURSE SEINE DI PERAIRAN KENDARI, PROVINSI SULAWESI TENGGARA
}

\author{
BUSINESS ANALYSIS OF PURSE SEINE NET FISHING \\ IN THE WATERS OF KENDARI, SOUTH EAST CELEBES PROVINCE
}

\author{
Suharyanto, Rahmad Surya Hadi Saputra*, M. Amin Mufid, dan \\ Dian Sutono
}

Politeknik Kelautan dan Perikanan Karawang, Jalan Lingkar Tanjungpura, Karangpawitan, Kecamatan Karawang Barat, Kabupaten Karawang, Jawa Barat 41315

Teregistrasi I tanggal: 07 Oktober 2019; Diterima setelah perbaikan tanggal: 30 Desember 2019; Disetujui terbit tanggal: 24 Januari 2020

\begin{abstract}
ABSTRAK
Usaha perikanan purse seine diperairan Kendari Sulawesi Tenggara banyak diminati oleh nelayan dengan besar kapal $\leq 30$ GT. Penelitian ini bertujuan untuk menganalisa kelayakan usaha perikanan purse seine di perairan Kendari. Secara keekonomian kegiatan perikanan tangkap KM. Tunas Harapan 99-02 dengan alat tangkap purse seine layak diusahakan, dengan beberapa parameter ekonomi masing-masing keuntungan sebesar Rp211.554.950,--; Net Present Value sebesar Rp816.808.430,--; Internal Rate of Return sebesar 23,35\%; Net B/C Ratio 1,80 dan Payback Period 4 tahun 9 bulan 22 hari. Sehingga untuk meningkatkan kinerja usaha agar lebih besar disarankan dengan menambah jumlah hari setiap trip penangkapannya yang dapat menghemat waktu dan biaya operasional.
\end{abstract}

Kata kunci: analisis usaha, purse seine, kelayakan

\begin{abstract}
The purse seine fishing business in Kendari Waters, Southeast Sulawesi is highly demand by local fishermen with fishing vessels $\leq 30$ GT. This study aims to analyze the feasibility of purse seine fisheries business in the waters of Kendari. The economics of capture fisheries activities KM of MV. Tunas Harapan 99-02 with purse seine fishing gear is feasible by looking the effort, with several economic parameters such as 1) Profit of Rp211,554,950, -; 2) Net Present Value of Rp.816,808,430, -; 3) Internal Rate of Return of 23.35\%; Net B / C Ratio 1.80 and 4) Payback Period 4 years 9 months 22 days. Increasing the number of days in each fishing trip will increase the performance of its business, so that it can save time and operational costs.
\end{abstract}

Keywords: Business analysis, purse seine, feasibility

\section{PENDAHULUAN}

Armada kapal yang beroperasi di perairan Kendari didominasi oleh kapal yang berukuran dibawah 5 GT, sedangkan diatas 10 - 30 GT beroperasi jauh hingga mencapai laut Banda. Alat tangkap yang banyak digunakan adalah pukat cincin (purse seine) untuk menangkap pelagis kecil dan besar (KKP, 2017). Namun selain purse seine ada beberapa jenis alat penangkapan ikan

Korespondensi penulis:

*Email: rahmad2002@gmail.com

DOI: http://dx.doi.org/10.15578/plgc.v1i1.8654 
(fishing gear) yang dioperasikan di perairan Kendari, Sulawesi Tenggara antara lain: jaring insang (gill net), bagan, payang, pancing rawai, pole and line, pancing kedo-kedo, sero, bubu rajungan, rawai, pancing ulur, pancing gurita, pancing tonda, panah (Speargun) dan pancing bambu (Halili, 2012).

Alat tangkap purse seine yang banyak digunakan oleh nelayan di perairan Kendari memiliki ukuran jaring mesh size dari ukuran jaring $\leq 2,5$ inci dan $\geq 3$ inci dengan panjang $\geq 100$ meter dan kedalaman 3-6 meter (KKP, 2017). Hal ini dapat mempengaruhi hasil tangkapan nelayan di pesisir Kendari, sehingga secara langsung juga dapat mempengaruhi pendapatan nelayan purse seine di perairan Kendari, Sulawesi Tenggara dibandingkan dengan beberapa nelayan yang menggunakan alat tangkap lainnya (Samida, Anadi, \& Abdullah, 2018).

Berdasarkan uraian diatas maka perlu dipelajari/dikaji terkait dengan kelayakan usaha perikanan tangkap dengan alat tangkap purse seine. Hal ini juga dapat dijadikan bahan kebijakan oleh pemerintah setempat terkait dengan keberlangsungan perikanan tangkap dengan alat tangkap purse seine. Sehingga tujuan penelitian ini adalah untuk mengetahui dan menganalisa kelayakan usaha perikanan purse seine di perairan Kendari dengan parameter perhitungan Rugi Laba, Net Present Value, Internal Rate of Return (IRR), Net B/C Ratio dan Payback Period (PBP).

\section{BAHAN DAN METODE}

Penelitian ini dilaksanakan pada bulan Maret sampai dengan bulan Juni 2019 di Pelabuhan Perikanan Samudera (PPS) Kendari dengan contoh pada KM. Tunas Harapan 99-02. Pengumpulan data primer dilakukan dengan mengikuti langsung operasi penangkapan ikan pada KM. Tunas Harapan 99-02 di perairan Laut Banda dengan alat tangkap Purse
Seine. Sedangkan data sekunder diperoleh dari hasil wawancara dengan pemilik kapal dan data informasi dari Pelabuhan Perikanan Samudera Kendari.

Analisa data dilakukan dengan cara menghitung beberapa parameter kriteria investasi, dengan rumus-rumus sebagai berikut.

\section{Rugi Laba}

Laba bersih dapat diperoleh dari seluruh penghasilan dikurangi seluruh biaya. Jika nilai selisih tersebut adalah positif, maka nilai tersebut sebagai keuntungan perusahaan, sedangkan nilai yang negatif menandakan kerugian perusahaan. Perhitungan rugi laba menggunakan rumus Coelli, Rao dan Bettese (1998), sesuai Pers. (1).

$$
\pi=T R-T C
$$

$$
\begin{array}{rlrl}
\text { Keterangan: } & & \\
\pi & = & \text { Pendapatan (keuntungan) } & \text { per } \\
& \text { trip } & & \\
T R= & \text { Total Revenue } & \text { (total } \\
& \text { penerimaan) per trip } \\
T C= & \text { Total Cost (Total biaya } \\
& \text { operasional) per trip }
\end{array}
$$

Dengan kriteria:

- Jika TR>TC, maka usaha purse seine mendapatkan keuntungan;

- Jika TR<TC, maka usaha purse seine mengalami kerugian;

- $\quad$ Jika TR=TC, maka usaha purse seine berada pada titik impas atau tidak untung ataupun rugi.

\section{Net B/C Ratio}

Net Benefit Cost Ratio (Net B/C Ratio) adalah perbandingan antara net benefit yang telah di discount positif dengan net benefit yang telah di discount negatif (Ibrahim, 2009). Net B/C Ratio dapat dihitung dengan Pers. (2). 


$$
N e t \frac{B}{C}=\sum_{i=1}^{n} \frac{N B(+)}{N B(-)}
$$

Selanjutnya Umar

memberikan kriteria Net B/C Ratio, sebagai berikut:

- B/C Ratio > 1: usaha menghasilkan keuntungan sehingga layak untuk dijalankan;

- $\mathrm{B} / \mathrm{C}$ Ratio = 1: usaha tidak menguntungkan dan tidak rugi (impas);

- B/C Ratio < 1: usaha mengalami kerugian sehingga tidak layak dijalankan.

\section{Net Present Value}

Menurut Umar (2003), Net Present Value adalah selisih antara present value dari investasi dengan nilai sekarang dari penerimaan-penerimaan kas bersih (aliran kas operasional maupun aliran kas terminal) di masa yang akan datang. Untuk menghitung nilai sekarang perlu ditentukan tingkat bunga yang relevan. Analisa NPV dapat diketahui dengan Pers. (3) (Ibrahim, 2009).

$$
\begin{aligned}
& N P V=\sum_{i=1}^{n} N B_{i}(1+i)^{-n} \\
& N P V=\sum_{i=1}^{n} \frac{N B_{i}}{(1+i)^{n}} \ldots \ldots \ldots \ldots \ldots
\end{aligned}
$$

Dimana:

$\mathrm{NB}=$ net benefit (benefit - cost)

$\mathrm{B}=$ benefit yang telah didiskon

$\mathrm{i}=$ discount factor

$\mathrm{n}=\operatorname{tahun}$ (waktu)

Dengan kriteria :

- NPV > 1 : maka usaha tersebut layak;

- NPV =0 : maka usaha tersebut dapat layak;

- $\quad$ NPV $<1$ : maka usaha tersebut tidak layak.

\section{Internal Rate of Return (IRR)}

Internal Rate of Return (IRR) adalah suatu tingkat discount rate yang menghasilkan Net Present Value sama dengan 0. Dengan demikian apabila hasil perhitungan IRR lebih besar dari Social Opportunity Cost of Capital (SOCC), dikatakan usaha tersebut feasible, bila sama dengan SOCC berarti pulang pokok dan dibawah SOCC proyek tersebut tidak feasible (Ibrahim, 2009). Dalam perhitungan digunakan rumus sesuai Pers. (4).

$I R R=i_{1}+\frac{N P V_{1}}{\left(N P V_{1}-N P V_{2}\right)} \cdot\left(i_{2}-i_{1}\right) \ldots \ldots$.

Dimana:

$$
\begin{aligned}
\mathrm{i}_{1}= & \text { adalah tingkat discount rate yang } \\
& \text { menghasilkan } \mathrm{NPV}_{1} \\
i_{2}= & \text { adalah tingkat discount rate yang } \\
& \text { menghasilkan } \mathrm{NPV}_{2}
\end{aligned}
$$

\section{Payback Period}

Payback period adalah sesuatu periode yang diperlukan untuk dapat menutup kembali pengeluaran investasi dengan menggunakan aliran kas neto. Dengan demikian payback period dari suatu investasi dengan menggambarkan panjangnya waktu yang diperlukan agar dana yang tertanam pada suatu investasi dapat diperoleh kembali seluruhnya (Riyanto, 1991). Menurut Ibrahim (2009), perhitungan payback period menggunakan rumus pada Pers. (5).

$$
P B P=T_{p-1}+\frac{\sum_{i=1}^{n} I_{i}-\sum_{i=1}^{n} B_{i c p-1}}{B_{p}} \ldots
$$

Dimana:

$$
\begin{aligned}
\mathrm{PBP}= & \text { payback period } \\
T_{p-1}= & \text { tahun sebelum dapat } \mathrm{PBP} \\
I_{i}= & \text { jumlah investasi yang telah di } \\
& \text { discount } \\
B_{i c p-1}= & \text { jumlah benefit yang telah di } \\
& \text { discount sebelum payback } \\
& \text { period } \\
B_{p}= & \text { jumlah benefit pada payback } \\
& \text { period }
\end{aligned}
$$


Selanjutnya Riyanto (1991), memberikan kriteria nilai payback period, sebagai berikut:

- Nilai payback period < 3 Tahun: Pengembalian modal usaha cepat;

- Nilai payback period 3 - 5 Tahun: Pengembalian modal usaha sedang;

- Nilai payback period > 3 Tahun: Pengembalian modal usaha lamban.

\section{HASIL DAN BAHASAN \\ HASIL}

Biaya Tetap

Berdasarkan hasil wawancara dengan pemilik kapal diperoleh data dan informasi terkait biaya tetap (Fix Cost) dalam pengoperasian KM. Tunas Harapan 99-02, yang meliputi pembiayaan investasi, usia ekonomis, penyusutan dan perawatan peralatan, serta biaya administrasi yang dikeluarkan dalam rangka pengoperasian KM. Tunas Harapan 99-02.

Dari hasil perhitungan diperoleh total biaya penyusutan sebesar Rp90.307.000,-- per tahun dari biaya investasi sebesar Rp1.011.170.000,-dengan perincian perhitungan sebagaimana Tabel 1.

Tabel 1. Pehitungan Biaya Penyusutan

Table 1. Calculation of depreciation cost

\begin{tabular}{clrcrr}
\hline No. & \multicolumn{1}{c}{ Jenis } & Harga (Rp) & $\begin{array}{c}\text { Umur } \\
\text { Ekonomis }\end{array}$ & Nilai Sisa & $\begin{array}{r}\text { Biaya Penyusutan/Thn } \\
(\text { Rp) }\end{array}$ \\
\hline 1. & Kapal & 640.000 .000 & 20 tahun & 50.000 .000 & 29.500 .000 \\
2. & Alat Tangkap & 300.000 .000 & 5 tahun & 25.000 .000 & 55.000 .000 \\
3. & Mesin Kapal & 60.000 .000 & 10 tahun & 15.000 .000 & 4.500 .000 \\
4. & GPS & 6.400 .000 & 8 tahun & & 800.000 \\
5. & Kompas & 1.200 .000 & 8 tahun & & 150.000 \\
6. & Radio VHF & 3.570 .000 & 10 tahun & 357.000 \\
\hline
\end{tabular}

Sumber : KM. Tunas Harapan 99-02 (2019)

Catatan: Nilai Sisa adalah harga saat ini, sedangkan biaya penyusutan harga karena umur pakai ekonomis.

Biaya perawatan kapal, motor penggerak dan alat tangkap dalam setiap tahunnya diperhitungkan sebesar Rp10.000.000,-- yang meliputi biaya docking/pengecatan kapal, service motor penggerak dan perbaikan alat tangkap purse seine.
Total biaya adminitrasi yang dikeluarkan setiap tahunnya pada pengoperasian KM. Tunas Harapan 99-02 sebesar Rp999.500,-- yang meliputi biaya perizinan dan surat-surat kapal dari biaya investasi Rp7.317.000,-- dengan perincian perhitungan seperti tersebut pada Tabel 2.

Tabel 2. Perhitungan Biaya Administrasi

Table 2. Calculation of administration cost

\begin{tabular}{clrcr}
\hline No. & Jenis & Harga $(\mathbf{R p})$ & Umur Ekonomis & Biaya Penyusutan/Tahun (Rp) \\
\hline 1. & Surat SIUP & 150.000 & 30 tahun & 7.500 \\
2. & Surat SIPI & 667.000 & 1 tahun & 667.000 \\
3. & Gross AKTE & 5.000 .000 & 20 tahun & 250.000 \\
4. & Surat Ukur & 1.500 .000 & 20 tahun & 75.000 \\
\hline & Total & 7.317 .000 & & 999.500 \\
\hline
\end{tabular}

Sumber : KM. Tunas Harapan 99-02 (2019)

Dengan demikian dalam pengoperasian KM. Tunas Harapan 99-02 diperlukan investasi Rp1.018.487.000,-- dan total biaya tetap setiap tahunnya sebesar Rp. 101.306.500,-- dengan perincian pada Tabel 3. 
Tabel 3. Total biaya tetap

Table 3. Fix cost

\begin{tabular}{|c|c|c|}
\hline No. & Jenis & Biaya Tetap (Rp) \\
\hline 1. & Biaya Penyusutan & $90.307 .000,--$ \\
\hline 2. & Biaya Perawatan & 10.000.000,-- \\
\hline 3. & Biaya Administrasi & $999.500,--$ \\
\hline & Total & $101.306 .500,--$ \\
\hline
\end{tabular}

\section{Biaya Tidak Tetap}

Perhitungan biaya tidak tetap (variable cost) dilakukan atas dasar hasil pengamatan catatan belanja perbekalan dan perhitungan bagi hasil dalam pengoperasian KM. Tunas Harapan 99-02 selama penelitian 5 (lima) trip penangkapan, dalam kurun waktu 24 (dua puluh empat) hari operasi. Dengan waktu persiapan sebelum berangkat kelaut serta perbaikan kapal (docking), motor penggerak dan alat tangkap purse seine, maka operasi penangkapan ikan dengan KM. Tunas Harapan 99-02 diasumsikan selama 10 bulan dalam setiap tahunnya. Dengan demikian semua biaya tidak tetap diperhitungan setiap bulan dan kemudian dikalikan 10 (sepuluh) dalam setiap tahunnya.

Hasil pengamatan selama 5 trip operasi penangkapan pada KM. Tunas Harapan 99-02 perincian biaya perbekalan terlihat pada Tabel 4. Dari perhitungan tersebut menunjukan bahwa total biaya perbekalan yang dibawa dalam 1 bulan dengan 5 (lima) trip operasi penangkapan adalah sebesar Rp74.091.000. Dengan asumsi 10 (sepuluh) bulan operasi penangkapan dalam setiap tahunnya, maka memerlukan biaya perbekalan sebesar Rp74.091.000,-- $\mathrm{x} 10$ bulan = Rp740.910.000,--.

Tabel 4. Biaya Perbekalan Table 4. Operational cost

\begin{tabular}{ccr}
\hline No. & Jenis & Biaya Perbekalan (Rp) \\
\hline 1. & Trip 1 & 19.955 .500 \\
2. & Trip 2 & 10.237 .500 \\
3. & Trip 3 & 14.624 .000 \\
4. & Trip 4 & 15.629 .000 \\
5. & Trip 5 & 13.645 .000 \\
\hline & Total & 74.091 .000 \\
\hline
\end{tabular}

Sesuai Peraturan Daerah (Perda) Provinsi Sulawesi Tenggara Nomor: 4 Tahun 2010 tentang Retribusi Izin Usaha Perikanan, setiap usaha penangkapan ikan dikenakan Pungutan Hasil Perikanan (PHP) sebesar $1 \%$ dari hasil produksi penangkapan setiap tahunnya. Berdasarkan tarif retribusi, usaha penangkapan ikan dengan KM. Tunas Harapan 99-02 dikenakan pungutan sebesar Rp15.986.050,-- setiap tahunnya, dengan perhitungan; $1 \% \mathrm{x}$ Rp1.598.605.000,-- = Rp15.986.050,--.

Upah tenaga didasarkan atas biaya-biaya yang dikeluarkan dan diterima oleh anak buah kapal (ABK), yaitu biaya bongkar muat perbekalan dan ikan hasil tangkapan serta perhitungan bagi hasil yang diterimakan kepada anak buah kapal. Biaya bongkar muat setiap trip operasi penangkapan adalah sebesar Rp4.000.000,-- sehingga dalam setiap tahunnya diperlukan biaya sebesar: Rp4.000.000,-- $\times 5$ trip $\times 10$ bulan = Rp.200.000.000,--. Sedangkan dari perhitungan bagi hasil selama satu tahun, anak buah kapal memperoleh bagian sebesar Rp.328.847.500,-- dengan perincian perhitungan sebagaimana tersebut pada uraian bagi hasil. Atas dasar perhitungan tersebut di atas, maka upah tenaga kerja yang dikeluarkan dalam satu tahun adalah sebesar Rp528.847.500,-yang terdiri atas upah bongkar muat sebesar Rp200.000.000,-- dan bagi hasil sebesar Rp328.847.500,--.

Dengan demikian biaya tidak tetap yang dikeluarkan setiap tahun dalam pengoperasian KM. Tunas Harapan 99-02 adalah sebesar Rp1.285.743.550,-- yang terdiri dari biaya perbekalan sebesar Rp740.910.000,--, retribusi Rp15.986.050,-- dan upah tenaga kerja sebesar Rp528.847.500,-- Sedangkan biaya keseluruhan yang dikeluarkan setiap tahunnya adalah sebesar Rp1.387.050.050,-- yang terdiri dari biaya tetap sebesar Rp101.306.500,-- dan biaya tidak tetap sebesar Rp1.285.743.550,--. 


\section{Penerimaan}

Hasil operasi penangkapan KM. Tunas Harapan 99-02 selama 5 (lima) trip operasi penangkapan sebesar Rp159.860.500,-- dengan perincian Tabel 5.

Tabel 5. Penerimaan

Table 5. Revenue

\begin{tabular}{ccr}
\hline No. & Jenis & Biaya Perbekalan $(\mathbf{R p})$ \\
\hline 1. & Trip 1 & $39.385 .000,--$ \\
2. & Trip 2 & $37.192 .000,--$ \\
3. & Trip 3 & $24.310 .000,--$ \\
4. & Trip 4 & $23.771 .500,--$ \\
5. & Trip 5 & $35.202 .000,--$ \\
\hline & Total & $159.860 .500,--$ \\
\hline
\end{tabular}

Dengan asumsi 10 (sepuluh) bulan operasi setiap tahunnya, maka penerimaan hasil operasi penangkapan KM. Tunas Harapan 99-02 dalam satu tahun adalah sebesar Rp1.598.605.000,--.

\section{Bagi Hasil}

Bagi hasil pada KM. Tunas Harapan 99-02 untuk anak buah kapal yang merupakan jenis biaya tidak tetap (upah tenaga kerja) sebesar Rp328.847.500, dengan perincian pada Tabel 6. Dari sisa antara hasil penjualan dan operasional kemudian dibagi dengan bagian ABK (50\%) sebesar Rp. 328.847.500,--.

Tabel 6. Bagi Hasil

Table 6. Profit Sharing

\begin{tabular}{clr}
\hline No. & \multicolumn{1}{c}{ Jenis } & Biaya Perbekalan (Rp) \\
\hline 1. & $\begin{array}{l}\text { Penerimaan hasil } \\
\text { penjualan ikan }\end{array}$ & $1.598 .605 .000,--$ \\
2. & $\begin{array}{l}\text { Biaya } \\
\text { Operasional }\end{array}$ & $940.910 .000,--$ \\
\hline & Sisa & $\mathbf{6 5 7 . 6 9 5 . 0 0 0 , - -}$ \\
\hline
\end{tabular}

\section{Pendapatan}

Hasil perhitungan laba bersih pengoperasian KM. Tunas Harapan 9902, diperoleh keuntungan setiap tahunnya sebesar Rp211.554.950,-- dengan perincian sebagai berikut:
- Penerimaan Hasil Penjualan Ikan $\quad$ : Rp1.598.605.000

- Biaya Operasional

- Keuntungan $: \frac{\operatorname{Rp} 1.387 .050 .050}{\operatorname{Rp~211.554.950}}$

Dari perhitungan analisa rugi laba tersebut diatas menunjukan bahwa dari modal investasi sebesar Rp1.018.487.000,-- dalam setiap tahunnya dapat menghasilkan keuntungan sebesar Rp211.554.950,--.

Net Present Value (NPV)

Dari perhitungan komponen investasi, biaya operasional dan discount rate sebesar $6,6 \%$, dalam pengoperasian KM. Tunas Harapan 99-02 didapatkan hasil Net Present Value (NPV) sebesar Rp816.508.430,--.

\section{Internal Rate of Return (IRR)}

Hasil perhitungan dari Social Opportunity Cost of Capital (SOCC) $16 \%$, diperoleh nilai Internal Rate of Return (IRR) sebesar 23,35\%, yang berarti bahwa usaha penangkapan ikan KM. Tunas Harapan 99-02 dengan alat tangkap purse seine layak (feasible) untuk dilaksanakan (IRR lebih besar dari nilai discount factor $16 \%$ ).

\section{Net B/C Ratio}

Hasil perhitungan perbandingan antara perolehan bersih (net benefit) yang telah di discount positif dengan yang di discount negatif dari pengoperasian KM. Tunas Harapan 99-02 dalam setiap tahunnya diperoleh nilai $\mathrm{Net} \mathrm{B} / \mathrm{C}$ Ratio sebesar 1,80 .

\section{Payback Periode (PBP)}

Dari hasil perhitungan arus penerimaan secara kumulatif dan present value investasi dalam pengoperasian KM. Tunas Harapan 99-02, diperoleh payback 
period (PBP) selama 4 tahun 9 bulan 22 hari.

\section{Hasil Tangkapan dan Daerah Penangkapan}

Hasil tangkapan utama pada operasi penangkapan KM. Tunas Harapan 99-02 selama penelitian diperoleh beberapa jenis ikan sebagaimana Tabel 7. Operasi penangkapan KM. Tunas Harapan 99-02 selama penelitian dilakukan sebanyak 5 (lima) trip, dengan daerah penangkapan ikan (fishing ground) di perairan Laut Banda pada koordinat antara lintang $03^{0}$ 46' 46" LS - 040 44' 29" LS dan bujur $124^{0} 16^{\prime} 06^{\prime}$ " BT - $125^{\circ} 45^{\prime} 06^{\prime \prime}$ BT, sebagaimana peta pada Gambar 1.

Tabel 7. Jenis ikan hasil tangkapan

Tabel 7. Fish catching effort

\begin{tabular}{llll}
\hline No. & Nama Ikan & Nama Daerah & Nama Latin \\
\hline 1. & Tuna Sirip Kuning & Bojo-bojo, & Thunnus albacares \\
2. & Cakalang & Jure & Katsuwonus pelamis \\
3. & Layang & Lajang & Decapterus spp. \\
4. & Lemadang & Lemadang & Coryphaena hippurus \\
5. & Tongkol & Tongkol & Euthynnus affinis \\
6. & Tenggiri & Tenggiri & Scomberomorus commerson \\
7. & kembung & Tombong & Rastrelliger kanagurta \\
8. & Ikan ayam- ayam & Pogoh & Abalistes stellaris \\
\hline
\end{tabular}

Sumber : KM. Tunas Harapan 99-02 (2019)

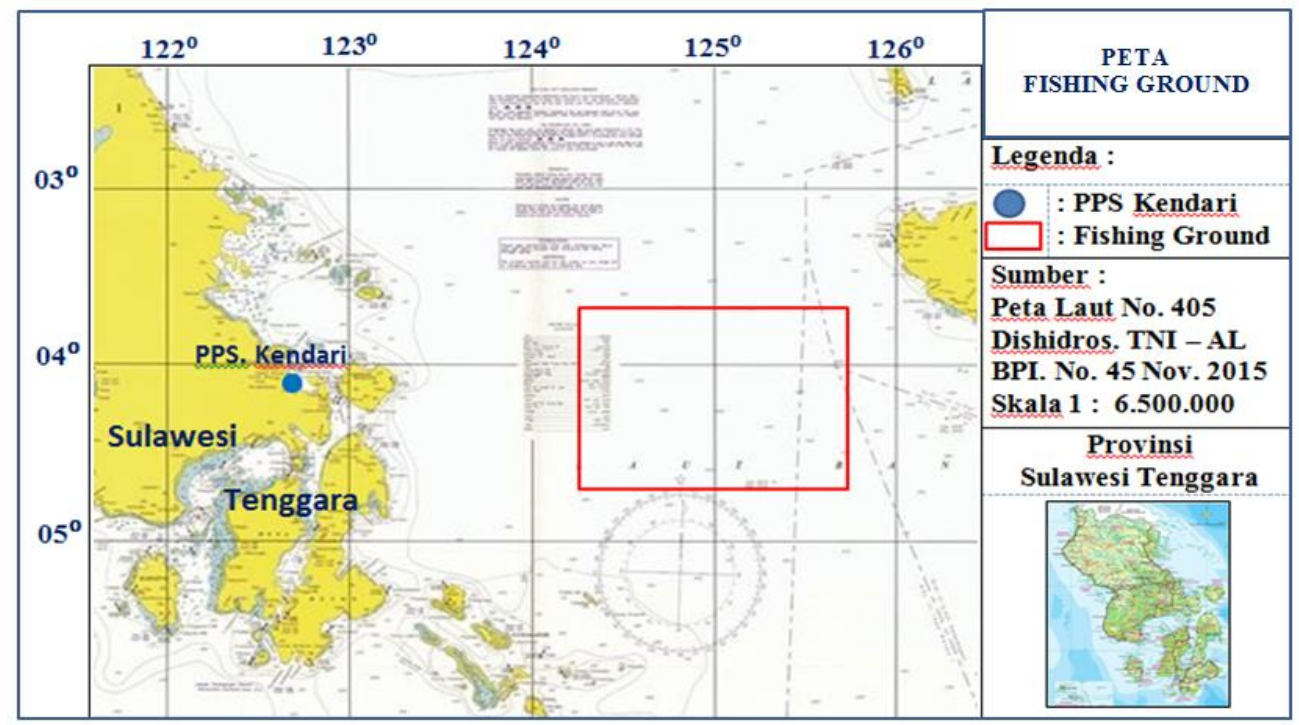

Gambar 1. Daerah Penangkapan Ikan

Figure 1. Fishing Ground

\section{BAHASAN}

Secara ekonomis pengoperasian KM. Tunas Harapan 99-02 layak diusahakan karena setiap tahunnya dapat menghasilkan keuntungan sebesar
Rp211.554.950. Sebagaimana dikatakan Ibrahim (2019), bahwa keuntungan (profit) adalah tujuan utama dalam pembukaan usaha/proyek yang direncanakan, semakin besar besar keuntungan yang diterima akan semakin 
layak usaha/proyek yang akan dikembangkan.

Dari perhitungan komponen investasi, biaya operasional dan discount rate sebesar $6,6 \%$, pengoperasian $\mathrm{KM}$. Tunas Harapan 99-02 yang menggunakan alat tangkap purse seine masih layak diusakan. Sebagaimana Ibrahim (2009) mangatakan, bahwa apabila hasil perhitungan net present value (NPV) lebih besar dari 0 (nol), maka usaha/proyek tersebut feasible (go) untuk dilaksanakan dan jika lebih kecil dari 0 (nol) tidak layak untuk dilaksanakan.

Selanjutnya Prasetyo et al. (2016) menyatakan, bahwa semakin tinggi net present value (NPV) suatu usaha, maka semakin layak pula usaha tersebut dan usaha yang dapat menaikan keuntungan yaitu usaha yang mempunyai net present value (NPV) yang lebih besar.

Diperoleh nilai IRR sebesar $23.35 \%$ yang berarti pengoperasian KM. Tunas Harapan 99-02 layak untuk dilaksanakan. Sebagaimana Ibrahim (2009), mengatakan bahwa proyek yang mempunyai IRR lebih besar dari social discount rate dinyatakan dengan feasible (go) dan untuk proyek-proyek yang lebih kecil dari SOCC dinyatakan tidak feasible (no go). Selanjutnya menurut Umar (2003) menyatakan, bahwa apabila IRR lebih besar dari nilai diskontrol berarti layak, apabila IRR lebih kecil dari tingkat diskontrol maka usaha itu tidak layak, dan apabila IRR sama dengan tingkat diskontro berarti berada dalam BEP.

Berdasarkan hasil perhitungan tersebut diatas menunjukan bahwa $\mathrm{Net}$ $B / C$ Ratio > 1, yang berarti bahwa kegiatan penangkapan ikan KM. Tunas Harapan 99-02 dengan alat tangkap purse seine layak untuk diusahakan. Sebagaimana dikatakan Ibrahim (2009), bahwa jika nilai net $B / C$ ratio lebih besar dari 1 (satu) berarti usaha tersebut layak untuk dikerjakan dan bila lebih kecil dari 1 (satu) berarti tidak layak untuk dikerjakan. Selanjutnya menurut Prasetyo et al. (2016), apabila $B / C$ ratio lebih besar dari satu maka usaha tersebut layak dan dapat diteruskan, apabila nilai $B / C$ ratio sama dengan satu maka usaha tersebut berada pada titik impas atau break event point, dan apabila nilai $B / C$ ratio kurang dari satu maka usaha tersebut tidak layak dan tidak dapat diteruskan

Berdasarkan perhitungan PBP menunjukkan bahwa biaya investasi akan kembali dalam kurun waktu 4 tahun 9 bulan dan 22 hari, artinya sebelum jangka waktu usia ekonomis kapal (20 tahun), motor penggerak (10 tahun) dan alat tangkap (5 tahun) sebagai komponen investasi utama habis, modal investasi sudah dapat diterima kembali yang dapat dipergunakan untuk kegiatan investasi berikutnya. Namun demikian jangka waktu pengambilan investasinya masih relatif lama (katagori sedang), yaitu lebih besar dari 3 tahun. Sebagaimana dikatakan Riyanto (1991), bahwa nilai payback period antara $3-5$ tahun termasuk dalam katagori pengembalian modal usaha sedang. Selanjutnya Ernaningsih (2008), mengatakan bahwa semakin cepat dalam pengembalian biaya investasi sebuah usaha, semakin baik pula usaha tersebut karena semakin lancar perputaran modalnya.

\section{SIMPULAN}

Dengan keuntungan yang
diterima lebih besar maka secara
keekonomian perikanan tangkap purse
seine layak untuk dikembangkan. Hal ini
dapat terjadi berdasarkan beberapa
parameter perhitungan yaitu NPV yang
memiliki nilai lebih besar dari pada Nol,
IRR lebih besar dari social discount rate,
Net B/C Ratio lebih besar dari 1, dan
payback period (PBP) dalam kategori
sedang.

\section{DAFTAR PUSTAKA}

Coelli, T., Rao, D. S. P., \& Bettese, G. E. (1998). An introduction to 
productivity analysis. United States of America: Springer.

Ernaningsih, D. (2008). Analisis usaha penangkapan ikan teri dengan bagan perahu di Teluk Jakarta. Jurnal Ilmiah Satya Negara Indonesia, 1 (2), 22-26. Jakarta: Universitas Satya Negara.

Gubernur Sulawesi Tenggara (2010). Peraturan Daerah Nomor; 4 Tahun 2010, tanggal 26 Agustus 2010, tentang Retribusi izin usaha perikanan. Kendari: Pemerintah Provinsi Sulawesi Tenggara.

Ibrahim, H. M. Y (2009). Studi Kelayakan Bisnis. Rineka Cipta. Jakarta.

Halili. (2012). Penilaian Performa Pengelolaan Perikanan menggunakan Indikator EAFM. Universitas, (September), 1-67. https://doi.org/10.14112/j.cnki.37 -1053/c.2016.s1.143.

KKP. (2017). Pusat Riset Perikanan Badan Riset dan Sumber Daya Manusia Kelautan dan Perikanan. Jakarta: KKP.
Prasetyo, A.B., Setiyanto, I., \& Hapsari, T.D. (2016). Analisis usaha perikanan tangkap kapal purse seine berpendingin freezer dibandingkan dengan es di Pelabuhan Perikanan Pantai (PPP) Bajomulyo, Juwana, Kabupaten Pati. Prosiding Seminar Nasional Tahunan ke - V Hasil Penelitian Perikanan. Semarang: Universitas Diponegoro.

Riyanto, B. (1991). Dasar-dasar Pembelanjaan Perusahaan, Yayasan Penerbit. Jakarta.

Samida, Anadi, L., \& Abdullah. (2018). Analisis pendapatan usaha Purse Seine di Pelabuhan Perikanan Samudera ( PPS ) Kendari dan faktor-faktor yang mempengaruhinya [Analysis Revenues of Purse Seine in the Kendari Ocean Fishing port and the Factors that Influence], 3(2), 125-134.

Umar, H. (2003). Studi kelayakan dalam bisnis jasa. PT. Gramedia Utama Pustaka, Jakarta. 